\title{
Partners search and quality-related information exchange in a virtual enterprise
}

\author{
L. M. Camarinha-Matos ${ }^{\text {I) }}$, H. Afsarmanesh ${ }^{2)}$, T. Cardoso $^{\text {I) }}$ \\ 1) New University of Lisbon, Quinta da Torre, 2825 Monte \\ Caparica, Portugal, \\ Tel: $+351-1-2948517$ \\ Fax: +351-1-2941253 \\ e-mail:cam@uninova.pt \\ ${ }^{2)}$ University of Amsterdam, Kruislaan 403, 1098 SJ \\ Amsterdam, The Netherlands \\ e-mail: hamideh@wins.uva.nl
}

\begin{abstract}
Partners search and selection is an important activity in the life cycle of a Virtual Enterprise. Among other factors, the commitment of the potential partners to fulfil quality requirements is a major decision criterion during the selection phase. An approach to search suppliers in suppliers' directories available on Internet is presented and the major negotiation steps leading to an adequate selection of partners are introduced. The quality-related information management functionalities required in a virtual enterprise support platform are also discussed.
\end{abstract}

\section{Keywords}

Virtual enterprises, partners search, quality management, federated information management.

\section{INTRODUCTION}

The selection of business partners is a very important and critical activity in the operation of a virtual enterprise (VE). Maintaining an updated list of suppliers with accurate information is considered an important asset of any industrial company. Similarly, for a VE, it is not only important to keep such lists, but also to develop 
mechanisms to access and evaluate the information provided by external directories of suppliers available on the Internet.

The need to select new partners arise both at the creation phase of a VE, when it is necessary to decide on the appropriate set of skills and resources required by the current business opportunity, or when it is necessary to replace a partner during the operation of a VE.

Among other factors, the commitment of the potential partners to quality requirements is becoming a major decision criterion. Quality management has become a major concern for manufacturing companies worldwide and a particularly critical topic for SMEs. It is noticeable the effort companies are making in order to get the ISO 9000 certification, a pre-condition to remain in the market and to be partners of supply chains and industrial virtual enterprises.

With the current tendency for distributing the manufacturing processes, as represented by the outsourcing movement and networked organizations in general, the responsibility for the quality is also distributed. As a consequence, some recent legislation, namely in Europe, allows a company to pass the responsibility related to the quality of a component / sub-product to the supplier of this component / subproduct. If a supplier that, on its turn, uses components provided by a third party, is not able to have accurate records of who supplied a defective component, then it becomes liable for the consequences of this defect. Therefore, it is of vital importance for every company, and particularly for those SMEs that do not have a tradition of keeping a well organized information system, to implement quality support systems appropriate for the operation in virtual enterprise / sub-contracting network.

The issue of quality-related information management starts when a company looks for new partners and negotiates the cooperation contracts. These contracts should include clauses related to the information that has to be exchanged / shared regarding quality. These contractual clauses have then to be enforced by an appropriate coordination system and supported by a infrastructure for virtual enterprises.

This paper represents a cooperative work between the Esprit PRODNET and the INCO-DC ProSME projects. The former is developing an infrastructure for virtual enterprises and the latter is studying the procedures for introducing quality management in SMEs. Both projects involve a cooperation between Europe and Latin America.

\section{PRODNET ARCHITECTURE}

The PRODNET II consortium designed and developed an infrastructure to support virtual enterprises. The Figure 1 shows the main components of this infrastructure that comprises three main blocks: The PRODNET Cooperation Layer (PCL), the Advanced Coordination Functionalities and the Company's Internal Module.

The so-called Internal Module represents the various legacy systems and applications that run in the enterprise like a Production Planning and Control (PPC) 
system or Enterprise Resources Planning (ERP) system, a CAD system, other engineering and internal tools. The PRODNET Cooperation Layer (PCL) is the responsible for supporting all interactions between a company and its VE partners.

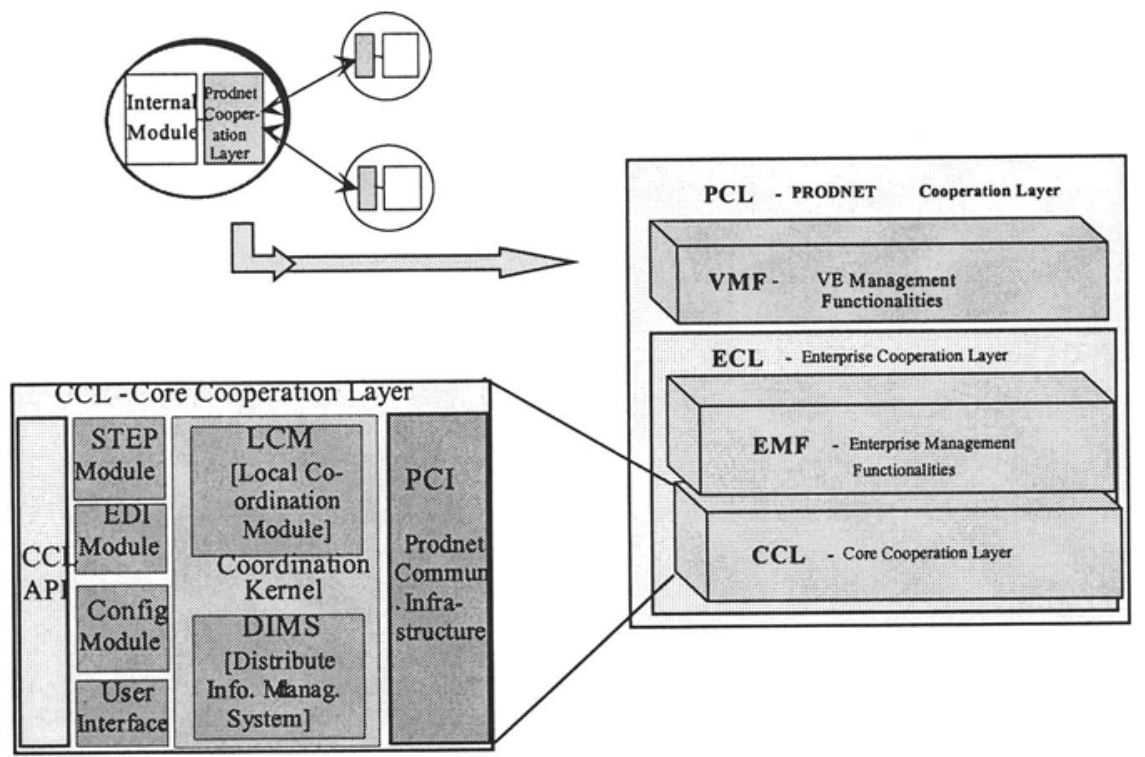

Figure 1 - PRODNET architecture

In order to facilitate the cooperation, all VE members should have an Enterprise Cooperation Layer (ECL), composed by the Core Cooperation Layer (CCL) and the Enterprise Management Functionalities EMF). The CCL includes: Safe communications, EDI and STEP based data exchange, definition of admission rights, definition of visibility rights on both the public information (e.g. directory of services / products), and explicitly shared information (e.g. order status and current job status at different enterprises), etc. The EMF module provides a ,reengineered" view of the enterprise's PPC/ERP systems suited to operate in a VE environment and includes services to support the management and monitoring of contracts among VE partners. This module supports the fulfillment of the duties of a company regarding the supply of quality information to its partners.

The VE Management Functionalities (VMF), also known in PRODNET II as Advanced Coordination functionalities, are used by the VE coordinator enterprise (Figure 2) and include, in the current implementation, ,partners search and selection" and ,distributed business processes management".

Details on this architecture can be found elsewhere (Camarinha-Matos et al., 1998), (Camarinha-Matos and Afsarmanesh, 1999).

An important aspect when ,inserting“ a company in a VE environment is the proper management of quality related information. In order to allow the definition of liabilities regarding quality in a scenario of distributed manufacturing it is necessary that each node is able to track all components involved in its products. 


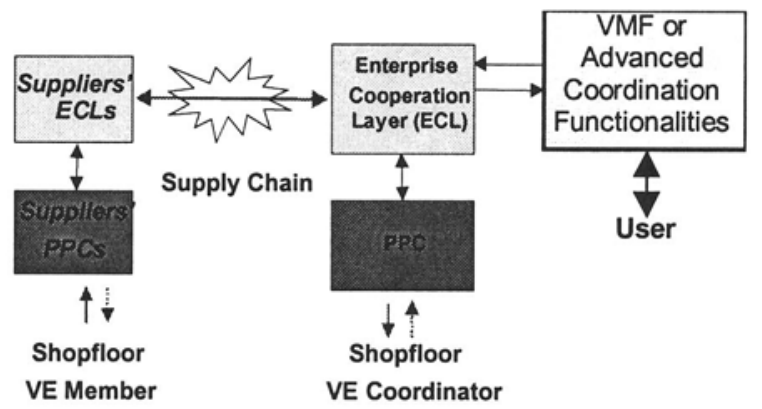

Figure 2 - Location of the advanced coordination functionalities

This functionality is included in the system developed in PRODNET II. The quality management has to be considered both at the enterprise level and at the VE level. At the enterprise level the proper ,place“ to locate the quality support functions is at the PPC system. Therefore, in PRODNET II a legacy system from the CSIN partner was extended with a quality management system covering the areas of: Parts reception and quality check procedures; Classification of suppliers; Tracing of purchasing orders and production orders. The developed functionality includes the following aspects:

- Configuration of general tables to support the quality control procedure. These tables include aspects such as Classes of tests (chemistry, mechanical, component level, system level, etc), Characteristics to be measured / tested (net weight, gross weight, etc), Measurement units, Parts reception codes (normal, controlled by controller, controlled by chief controller, etc), etc. In this definition the EDIFACT recommendations were followed.

- Definition of rules for technical Parts Reception (quality verification process).

- Launching of an automatic control procedure according to the quality verification conditions configured for each supplier / partner. In other words, the system can monitor and enforce the verification process defined for each supplier. This process involves the management of all associated documents and generation of verification commands for the Quality department.

The verification procedure to apply may vary from supplier to supplier. Suppliers are classified according to a number of factors reflecting the past behavior of these companies regarding quality aspects and compliance with ISO 9000. Keeping a record of a supplier's performance in past cooperation activities will influence its selection or rejection for a future business opportunity.

Results of the parts acceptance procedure, together with a reference to the corresponding suppliers / partners, are kept in a historic database allowing for future trace of the distributed responsibilities involved in each product.

At the VE level two forms of exchange of quality related information are considered:

i. On demand. The VE coordinator (or a client partner) may request information about a specific part ordered from a partner (supplier). 
ii. By contract. The supplier is supposed to send, by contractual agreement, to the VE coordinator or other VE partners, information about the status of the business processes taking place at its site, including the quality related aspects. This information might have to be supplied on a periodic basis (e.g. every week), or when the part is delivered, depending on the contractual clauses.

In order to support these requirements, the PRODNET infrastructure implements two inter-related mechanisms that provide for a high level of flexibility: Workflow-based coordination; Federated information management.

By the adoption of workflow-based coordination mechanisms (CamarinhaMatos and Lima, 1998), at various levels of abstraction as implicit in the multilevel architecture, it is rather easy to specify the desired behavior for the VE and for each VE member. Depending on the cooperation agreements established between VE partners, a set of workflow plans are easily defined, via a graphical editor, regulating the way PCL has to react to incoming events or to cyclic / timecontrolled activities. An extensive list of coordination primitives, including flows with conditioned transitions, and/xor split/join mechanisms, sub-workflows, temporized and cyclic activities, interaction between workflow plans of different levels, and working space management for parameter passing when activating services, are implemented.

The federated / distributed information management component (DIMS) is responsible to model and manage the exchange of all integrated cooperationrelated information, while preserving the autonomy and information privacy of involved enterprises. Different levels of information visibility for other enterprises, defined at every enterprise, guarantee the enterprise's autonomy on sharing its information. In the general case, two kinds of queries may arrive at a DIMS, an internal query (a query arriving from the PPC or other PCL modules in the node) or an external query (a query arriving from another node's DIMS). Furthermore, there are two kinds of internal queries that need to be handled. The query can be a local query which can be answered without acquiring any information from other nodes, or it can be a query that needs information from external nodes, i.e. a distributed query, which involves the retrieving of information from one or a specific set of nodes. The coordination of the various events / activities involved in this complex process is guaranteed by a set of workflow plans designed to operate in close interaction with the services offered by DIMS.

\section{PARTNERS SEARCH}

Selection of business partners is a very important activity during the life cycle of a Virtual Enterprise (Molina et al., 1998). This need comes first with the creation phase of a virtual enterprise. When a new business opportunity is detected, the initiator of the VE has to look for the most suitable partners for the new consortium. The "core partners" come most naturally from the internal list of 
previous partners, but other partners are searched for in other sources of information. Furthermore, in a very ,volatile“ VE, which dynamically changes its composition, in a non-predefined way, partners / suppliers may be unknown $a$ priori. On the other hand, even during the normal operation of a ,stabilized“ VE, it might be necessary to find suppliers for a particular component or service not offered by other VE members. Another important case for this activity is in the case of unexpected events. When, during its operation, a VE member has problems in finishing / fulfilling some contracted business process, one of the possible reactions of the VE Coordinator is to look for a substitute supplier.

Partners search can be based on two major information sources: External Suppliers Directories and Enterprise Private Suppliers List. The former is a new service already existing for several countries composed of national databases of enterprises. Almost all of those directories also have an associated search engine connected to the WWW. The Enterprise Private Suppliers List is a data repository that contains information about the companies that have had commercial relationships with this enterprise. The way the business ran in the past relationships is the key element for choosing one supplier among a set of potential enterprises. Actually, information like delays on delivery time, quality references, or a good client support reference can become the deciding criteria between two potential suppliers. This kind of information can normally be managed by the PPC system, as in the case of PRODNET, but it is difficult to get this information about new suppliers.

The mentioned information sources suggest the split of the search into two phases. The first one based on a local supplier's directory and the second one based on the external suppliers' lists. The second source is only used if the first fails or if the results are not considered satisfactory.

The most challenging part is the partners' search and selection based on External Suppliers Directories available on the Internet. The next figure illustrates the approach followed by PRODNET to support this process, which includes the following main steps (Figure 3): define general profile for partners search (general query generation), send query to selected External Suppliers Directories, receive and filter results, generate „Call for Tenders“ and send it to potential suppliers, collect bids, and decide on the partners to be selected. Another functionality, not implemented yet, could support the generation of contracts between the VE and the newly selected partners.

The Call for Tenders can in fact split into several phases (Figure 4), such as: Call for Tenders generation, Call for Tenders dissemination, Reception of Bids, Negotiation of contracts, Contract award, etc.

The Partners Search tool, developed by the New University of Lisbon, supports the partners' search and selection through the public directories of suppliers available on the Internet. 


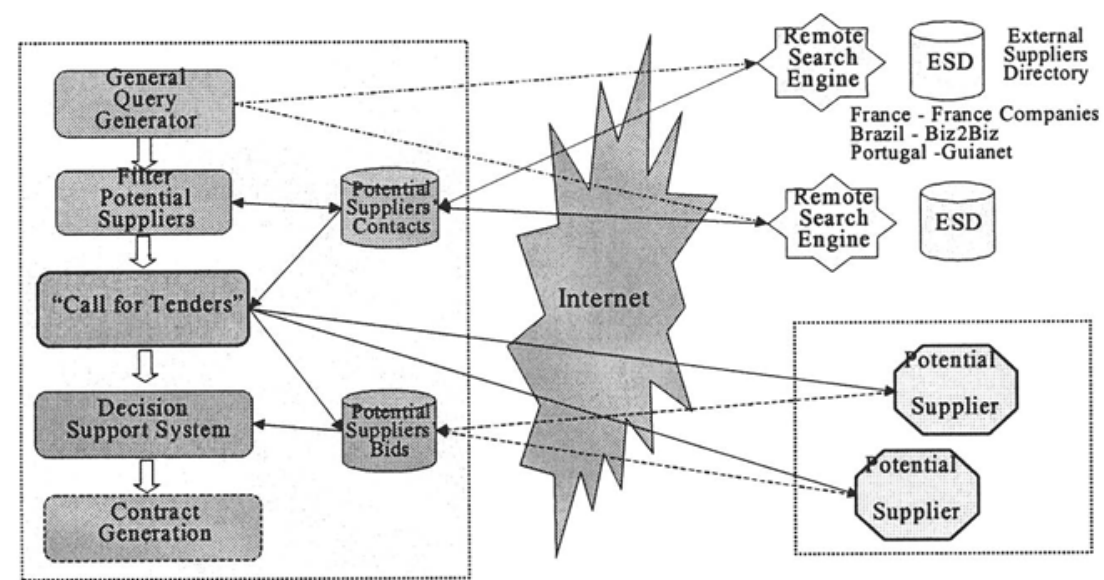

Figure 3 - Partners search based on external suppliers' directories

The main characteristics of this prototype include:

- Searches based on access to three directory services: Biz2Biz, France Companies, and GuiaNet.

- Filtering of results according to user defined criteria

- Generation of Web-based Call for Tenders and e-mail notification for the potential partners

- Bids management

- Simple multi-criteria classification / decision support system for received bids.

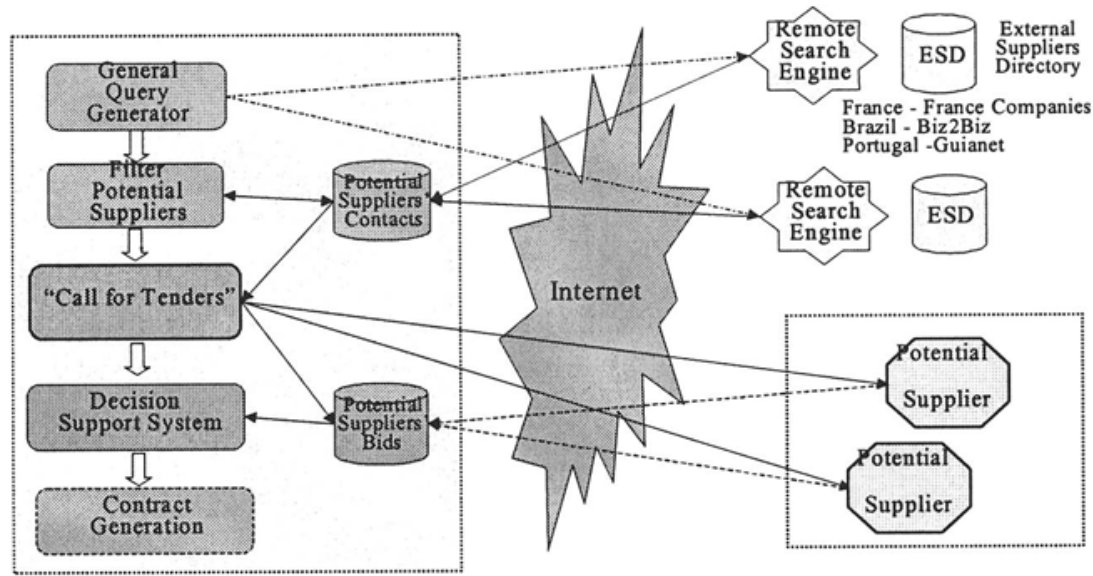

Figure 4 - Biding and negotiation in partners' search

The quality related aspects represent one of the items to be negotiated in this process. Resulting clauses may define, for instance, which information a company 
has to share with its partners, which information has to be automatically sent to the partner on a periodic basis, which formats / standards to be used, etc.

These clauses are then instantiated in the PRODNET Cooperation Layer (PCL), and controlled by the coordination / information sharing component of the PRODNET Infrastructure, that supports the contract enforcement during the VE operation. In particular, the workflow-based coordination module (LCM) of PCL, manages the flow of activities and events involved in the business cooperation, and the federated / distributed Information Management module (DIMS), manages the information sharing and exchange, taking into account the access rights and privacy of each partner.

\section{CONCLUSIONS}

Quality-related information sharing is a very important topic in a VE environment, both during partners search and selection and during the VE operation and dissolution.

The infrastructure developed by PRODNET II offers a flexible approach to the coordination and information management, including the quality aspects, both at the enterprise level and VE level. The partners search and selection mechanisms also take into account the quality management requirements, namely when selecting a partner and establishing the cooperation agreements.

Finally, the ProSME project is contributing with the analysis of the practices and requirements for quality management introduction in SMEs, namely in VE and sub-contracting environments.

Acknowledgements. This work was funded in part by the European Commission, Esprit and INCO programs within the PRODNET II and ProSME projects. The authors also thank the valuable contributions from the PRODNET II consortium partners: CSIN (P), ESTEC (P), HERTEN (BR), Lichen Informatique (F), MIRALAGO (P), ProSTEP(D), Uninova (P), University of Amsterdam (NL), Universidade Federal de Santa Catarina (BR), and Universidade Nova de Lisboa (P), and ProSME partners: ATB (D), UFRGS (BR), GloboInox (BR), UNICEN (AR), and Universidade Nova de Lisboa (P).

\section{REFERENCES}

Camarinha-Matos, L.M.; Afsarmanesh, H. - Infrastructures for Virtual Enterprises, Kluwer Academic Publishers (to appear), 1999.

Camarinha-Matos, L.M.; Afsarmanesh, H; Garita, C.; Lima, C. - Towards an architecture for virtual enterprisesJournal of Intelligent Manufacturing, Vol. 9, Issue 2, Abr 1998, pp 189-199. 
Camarinha-Matos, L.M.; Lima - Configuration and coordination issues in a virtual enterprise environment, Proceedings of PROLAMAT'98, Trento, Italy, 9-12 Sep 98.

Molina, A.; Flores, M.; Caballero, D. - „Virtual Enterprises: A Mexican case study“. In Intelligent Systems for Manufacturing, L.M. Camarinha-Matos, H. Afsarmanesh, V. Marik, ed.s, Boston: Kluwer Academic Publishers, Aug 1998. 